\title{
Clinical Reasoning: An 11-year-old girl with focal seizures, fevers, and unilateral, enhancing cortical lesions
}

Jeffrey B. Russ, MD, PhD, Clare M. Timbie, MD, PhD, Yi Li, MD, and Ernesto Gonzalez-Giraldo, MD

Neurology ${ }^{\circledR}$ 2020;95:e3153-e3159. doi:10.1212/WNL.0000000000010655

\section{Section 1}

An 11-year-old girl with no relevant medical history experienced acute-onset confusion and speech arrest without loss of consciousness, eye deviation, tonic stiffening, or convulsion. At an outside emergency department, her examination included expressive aphasia, right lower facial droop, and right-sided hemiparesis. Noncontrast head CT was negative for acute intracranial pathology, CT angiogram showed patent vasculature, and CT perfusion showed no areas of perfusion mismatch. The patient was transferred to our institution for further management.

On arrival, the patient was afebrile without meningismus, and her neurologic examination had improved substantially with mild expressive aphasia, slight right nasolabial fold flattening, and distal right upper extremity weakness. Over the next day, she had recurrent paroxysmal episodes of confusion, aphasia, right arm tonic stiffening, and subsequent right hemiparesis.

\section{Questions for consideration:}

1. What is the differential for pediatric patients with acute-onset aphasia and hemiparesis?

2. If the episodes were seizures, what lateralization/localization would you suspect for their onset based on semiology?

\author{
Correspondence \\ Dr. Gonzalez-Giraldo \\ ernesto.gonzalez-giraldo@ \\ ucsf.edu
}

GO TO SECTION 2 


\section{Section 2}

$\mathrm{MRI} /$ magnetic resonance angiography brain demonstrated left parietal and perirolandic cortical edema with some reduced diffusion but no abnormal enhancement, overt ischemia, or structural abnormalities (figure 1). Magnetic resonance spectroscopy over the involved area was normal. An EEG showed left posterior quadrant slowing with occasional left posterior temporal sharp waves and multiple electrographic seizures originating from the left posterior quadrant (figure 1), consistent with her aphasic seizures and postictal Todd paralysis. ${ }^{1}$ The focal tonic features were thought to represent spread to the left frontal lobe. ${ }^{1}$ The patient was started on levetiracetam (60 $\mathrm{mg} / \mathrm{kg} / \mathrm{d}$ ). Because she was initially afebrile without meningismus, and because her CSF studies (below) did not suggest bacterial or herpes simplex virus (HSV) meningoencephalitis, she was not empirically given antimicrobials.

On the 5th day of admission, the patient became intermittently febrile with temperatures up to $39.4^{\circ} \mathrm{C}$. At this time, the differential for her acute-onset focal seizures was broad and included infectious, autoimmune, neoplastic, and metabolic possibilities (table).
Serum infectious studies were negative. A serum autoimmune encephalopathy panel was negative. Antinuclear antibodies (ANAs) were positive with a nucleolar pattern and a titer of 1:320, but erythrocyte sedimentation rate, C-reactive protein, dsDNA, rheumatoid factor, and SSA/SSB were unremarkable. Serum metabolic studies, including ammonia, lactate, pyruvate, amino acids, free and total carnitine, and acylcarnitine profile, were normal. Urine organic acids were normal.

Lumbar puncture demonstrated a mixed pleocytosis: 35 white blood cells with $40 \%$ neutrophils, $47 \%$ lymphocytes, and $13 \%$ monocytes. CSF glucose, protein, lactate, pyruvate, and immunoglobulin $\mathrm{G}$ ( $\operatorname{IgG}$ ) index were unremarkable and there were zero oligoclonal bands. A CSF autoimmune encephalopathy panel was negative. CSF HSV, varicella-zoster virus, enterovirus, West Nile virus, and bacterial culture were negative. Metagenomic nextgeneration sequencing for organisms was performed and resulted in a subthreshold positive result for Candida glabrata, which was believed to be a contaminant, particularly in an immunocompetent host. Repeat CSF metagenomic testing was negative. CSF cytology demonstrated lymphocytosis but no atypical cells.

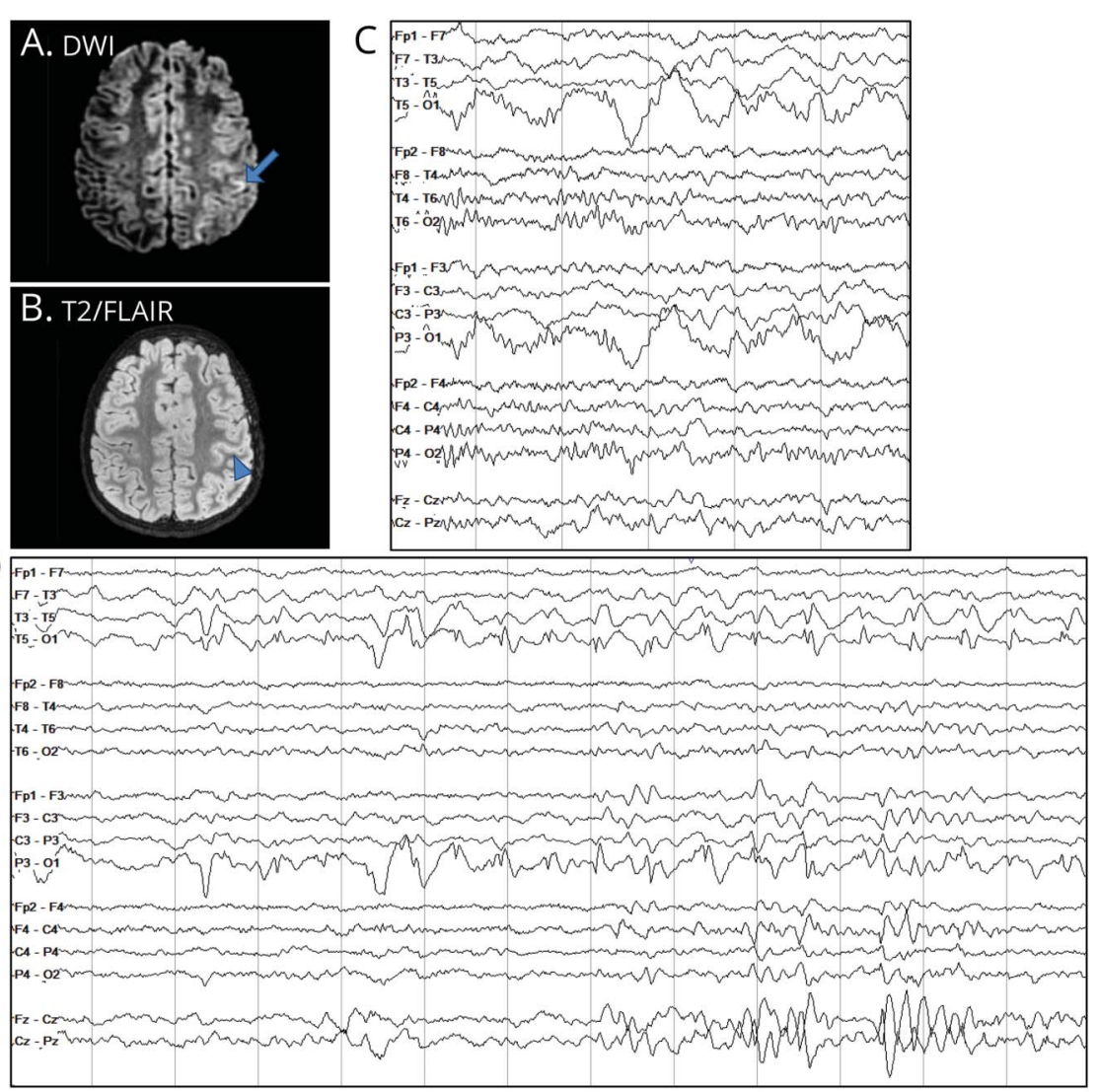

(A, B) Initial MRI brain at the onset of symptoms demonstrates reduced diffusion in in the left supramarginal gyrus ( $\mathrm{A}$; arrow), as well as cortical edema in the left perirolandic cortex (B; arrowhead). (C, D) EEG, shown in a longitudinal bipolar montage, demonstrates marked interhemispheric asymmetry with focal slowing maximal in the left posterior quadrant (C), and the onset of an electrographic seizure with emergence of rhythmic left posterior spikes with evolution in frequency and morphology. DWI = diffusion-weighted imaging; FLAIR = fluid-attenuated inversion recovery. 
Table Comprehensive summary of the serum, CSF, and urine studies obtained as part of the patient's evaluation

\begin{tabular}{|c|c|}
\hline & Values \\
\hline \multicolumn{2}{|l|}{ Autoimmune/inflammatory } \\
\hline \multicolumn{2}{|l|}{ Serum } \\
\hline $\mathrm{ESR}^{\mathrm{a}}$ & $35 \mathrm{~mm} / \mathrm{h}$ \\
\hline CRP & $<0.02$ \\
\hline ANA $^{a}$ & $1: 320$ \\
\hline dsDNA & $<10$ \\
\hline $\begin{array}{l}\text { Rheumatoid } \\
\text { factor }\end{array}$ & $<40$ \\
\hline SSA/SSB & $<5$ \\
\hline Anti-Smith & 16.2 \\
\hline Anti-RNP & $<10.0$ \\
\hline PANCA/cANCA & $<10$ \\
\hline ACE & 46 \\
\hline Ribosomal antibody & $<1$ \\
\hline Lysozyme & $4.6 \mu \mathrm{g} / \mathrm{mL}$ \\
\hline anti-TPO $^{a}$ & $1: 200$ \\
\hline TSI & 101 \\
\hline Thyroglobulin & $<2 \mathrm{IU} / \mathrm{mL}$ \\
\hline $\begin{array}{l}\text { Antiphospholipid antibody } \\
\text { panel }\end{array}$ & Negative \\
\hline $\begin{array}{l}\text { Autoimmune encephalopathy } \\
\text { panel }\end{array}$ & Negative \\
\hline Anti-NMO/AQP4 & Negative \\
\hline Anti-MOG ${ }^{a}$ & $1: 1,000$ \\
\hline Ferritin & $48 \mu \mathrm{g} / \mathrm{L}$ \\
\hline Fibrinogen $^{a}$ & $498 \mathrm{mg} / \mathrm{dL}$ \\
\hline Soluble IL-2 & 970 \\
\hline Functional NK cells & 6 LU30 \\
\hline Lymphocyte subsets & WNL \\
\hline \multicolumn{2}{|l|}{ CSF } \\
\hline $\begin{array}{l}\text { Autoimmune encephalopathy } \\
\text { panel }\end{array}$ & Negative \\
\hline \multicolumn{2}{|l|}{ Infectious } \\
\hline \multicolumn{2}{|l|}{ Serum } \\
\hline EBV PCR & Negative \\
\hline West Nile virus IgG & Negative \\
\hline West Nile virus IgM & Negative \\
\hline Quantiferon & Negative \\
\hline Histoplasma & Negative \\
\hline Chlamydia psittacosis & Negative \\
\hline
\end{tabular}

Table Comprehensive summary of the serum, CSF, and urine studies obtained as part of the patient's evaluation (continued)

\begin{tabular}{|c|c|}
\hline & Values \\
\hline \multicolumn{2}{|l|}{ CSF } \\
\hline HSV PCR & Negative \\
\hline VZV PCR & Negative \\
\hline Enterovirus & Negative \\
\hline EBV PCR & Negative \\
\hline West Nile virus IgM & Negative \\
\hline West Nile virus IgG & Negative \\
\hline$\beta$-d-glucan & $<60 \mathrm{pg} / \mathrm{mL}$ \\
\hline Cryptococcal antigen & Negative \\
\hline Fungal culture & Negative \\
\hline Bacterial culture & Negative \\
\hline Urine histoplasma & Negative \\
\hline \multicolumn{2}{|l|}{ Metabolic } \\
\hline \multicolumn{2}{|l|}{ Serum } \\
\hline Ammonia & $17 \mu \mathrm{mol} / \mathrm{L}$ \\
\hline Lactate & $1.3 \mathrm{mmol} / \mathrm{L}$ \\
\hline Pyruvate & $1.1 \mathrm{mg} / \mathrm{dL}$ \\
\hline Amino acids & WNL \\
\hline Free carnitine & $44.7 \mu \mathrm{mol} / \mathrm{L}$ \\
\hline Total carnitine & $58.2 \mu \mathrm{mol} / \mathrm{L}$ \\
\hline Acyl/free carnitine ratio & 0.3 \\
\hline Acylcarnitine profile & WNL \\
\hline \multicolumn{2}{|l|}{ CSF } \\
\hline Lactate & $1.4 \mathrm{mmol} / \mathrm{L}$ \\
\hline Pyruvate & $1.7 \mathrm{mg} / \mathrm{dL}$ \\
\hline \multicolumn{2}{|l|}{ Urine } \\
\hline Organic acids & WNL \\
\hline \multicolumn{2}{|l|}{ Endocrine } \\
\hline \multicolumn{2}{|l|}{ Serum } \\
\hline TSH & $0.39 \mathrm{mIU} / \mathrm{L}$ \\
\hline Free T4 & $14 \mathrm{pmol} / \mathrm{L}$ \\
\hline T3 & $2.8 \mathrm{pg} / \mathrm{mL}$ \\
\hline Neoplastic CSF cytology & Negative \\
\hline
\end{tabular}

Abbreviations: $\mathrm{ACE}$ = angiotensin-converting enzyme; $\mathrm{ANA}=$ antinuclear antibodies; CANCA = cytoplasmic antineutrophil cytoplasmic antibodies; CRP = C-reactive protein; $\mathrm{EBV}=$ Epstein-Barr virus; $\mathrm{ESR}=$ erythrocyte sedimentation rate; HSV = herpes simplex virus; IgG = immunoglobulin G; IgM = immunoglobulin $\mathrm{M}$; IL = interleukin; MOG = myelin oligodendrocyte glycoprotein; NK = natural killer; NMO = neuromyelitis optica; pANCA = perinuclear antineutrophil cytoplasmic antibodies; TPO = thyroid peroxidase; TSH = thyroid-stimulating hormone; TSI = thyroid stimulating immunoglobulin; VZV = varicella-zoster virus; $\mathrm{WNL}$ = within normal limits.

a Abnormal values. 


\section{Questions for consideration:}

1. Based on these results, how would you prioritize the differential diagnosis?
2. Would you start any empiric therapies?

GO TO SECTION 3 


\section{Section 3}

Based on the patient's elevated ANA, mixed CSF pleocytosis, and unrevealing infectious, metabolic, and neoplastic workup, an inflammatory/autoimmune process was favored. She was started on empiric high-dose methylprednisolone $(30 \mathrm{mg} / \mathrm{kg} / \mathrm{d})$ and discharged on a prednisone taper with a plan to continue management as an outpatient.

In the interval, the patient had no further fevers or seizures. She had near-complete return to baseline with only subtle acalculia and dysgraphia. When an outpatient surveillance MRI demonstrated new enhancing lesions in the left frontal and insular subcortical white matter (figure 2), she was readmitted for expedited evaluation.

While inpatient, the patient was again febrile with temperatures as high as $39.5^{\circ} \mathrm{C}$ and had 2 seizures with acute confusion and aphasia. EEG again demonstrated a left posterior quadrant origin. Lacosamide $(5 \mathrm{mg} / \mathrm{kg} / \mathrm{d})$ prevented further seizures.

In consultation with our infectious disease and rheumatology colleagues, additional studies were sent to further consider infectious, autoimmune, endocrine, and neoplastic etiologies (table). Autoinflammatory diseases and genetic disorders of the innate immune system with heterogeneous CNS manifestations ${ }^{2}$ were considered, but the time course and absence of typically associated non-neurologic inflammatory symptoms suggested an acquired autoimmune disorder.

Repeat lumbar puncture demonstrated a mixed pleocytosis (41 white blood cells with 55\% lymphocytes, $28 \%$ neutrophils, $16 \%$ monocytes, and $1 \%$ eosinophils) with an unremarkable glucose and protein. CSF IgG index was 0.7 and there were zero oligoclonal bands. Ophthalmologic examination was normal. Interval imaging demonstrated new areas of left-sided linear intraparenchymal enhancement, cortical and subcortical fluid-attenuated inversion recovery (FLAIR) hyperintensity, and leptomeningeal enhancement, in addition to evolution of the prior findings (figure 2). MRI spine was normal.
Figure 2 Repeat MRI findings
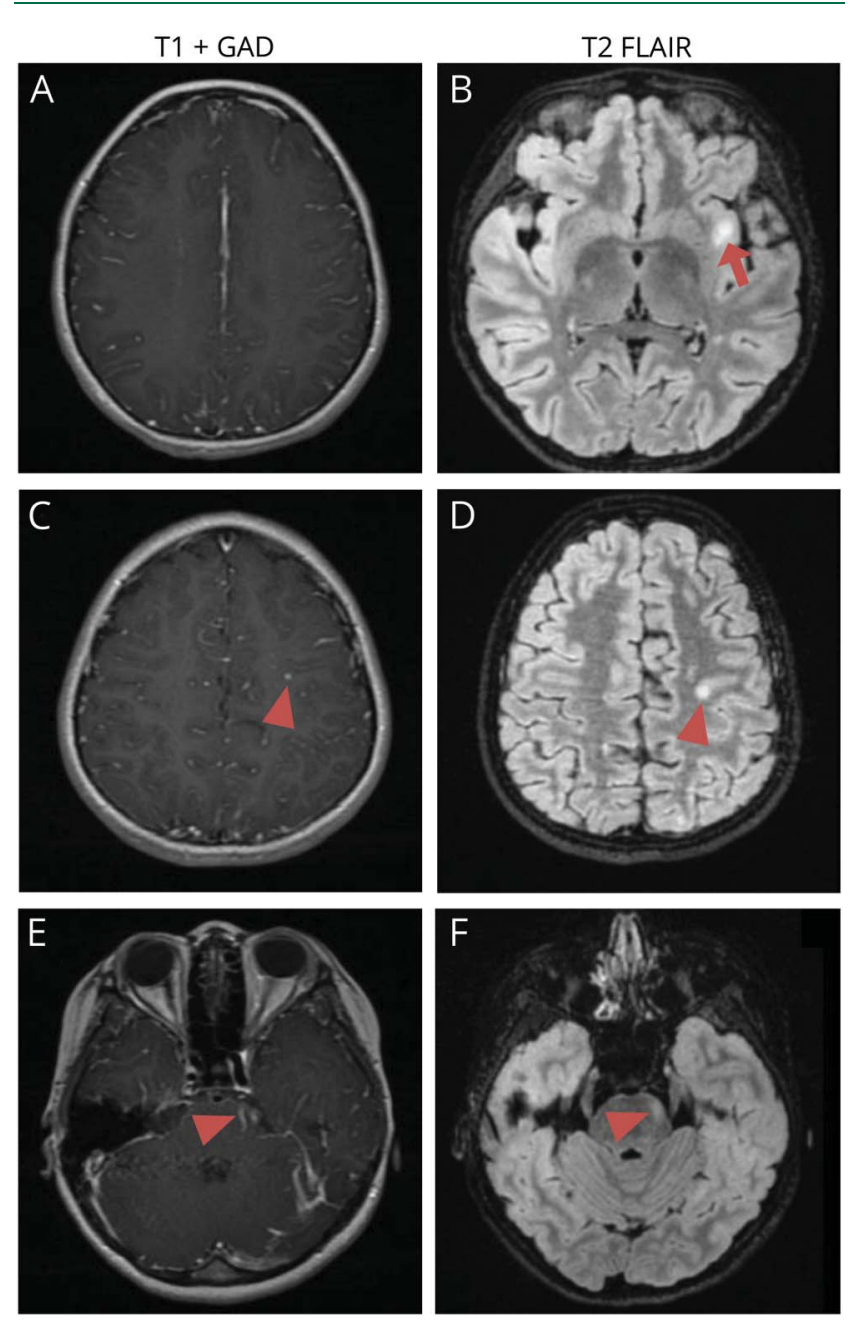

Subsequent MRI during the second admission demonstrates multiple foci of subcortical fluid-attenuated inversion recovery (FLAIR) hyperintensity with associated punctate and linear enhancement (arrowheads A-F), cortical thickening and FLAIR hyperintensity (arrow, B), and leptomeningeal enhancement (arrowhead, C). Of note, the pontine lesion (F) surrounds a linear area of enhancement $(E)$, which may reflect an engorged vessel.

\section{Questions for consideration:}

1. Does the differential diagnosis change with these findings?

2. Is there targeted testing you would send to confirm a diagnosis? 


\section{Section 4}

Anti-myelin oligodendrocyte glycoprotein (MOG) IgG, tested at Mayo Laboratories via a cell-based assay employing full-length MOG antigen, ${ }^{3}$ returned positive with a titer of 1 : 1,000 . The presentation was consistent with a newly described MOG-antibody-associated phenotype called FLAIRhyperintense lesions in anti-MOG-associated encephalitis with seizures (FLAMES). ${ }^{4}$ The patient was restarted on 5 days of methylprednisolone $(30 \mathrm{mg} / \mathrm{kg} / \mathrm{d})$ followed by an 8 week prednisone taper, and she received a single dose of rituximab $\left(750 \mathrm{mg} / \mathrm{m}^{2}\right)$. Given that her symptoms were not highly debilitating, we opted for steroids over IV immunoglobulin or plasmapheresis, following an accepted approach to pediatric anti-MOG-associated disease. ${ }^{5}$

After discontinuing prednisone, the patient returned with left optic neuritis. MRI brain demonstrated no other new lesions. Lymphocyte subsets demonstrated persistent B-cell depletion after rituximab. The patient repeated 5 days of pulse-dose steroids with visual improvement and was discharged on a prolonged course of prednisone (60 mg daily) and a plan to follow up in the neuroimmunology clinic.

\section{Discussion}

Since its detection in children with autoimmune neuroinflammatory disorders, ${ }^{6}$ anti-MOG antibody has identified a phenotypically diverse subpopulation of patients with autoimmune CNS disorders. Pediatric anti-MOG-associated disease is prevalent; a recent prospective study found that $22 \%$ of pediatric patients diagnosed with encephalitis or acquired demyelinating disease were positive for anti-MOG antibody. ${ }^{7}$ Various case series have described the presentations of pediatric vs adult anti-MOGassociated disorders, revealing some general themes: patients with anti-MOG antibodies tend to be younger than patients with neuromyelitis optica (NMO) or multiple sclerosis (MS); they rarely meet MS diagnostic criteria; they often present with optic neuritis, myelitis, or acute disseminated encephalomyelitis; they often have radiographic involvement of supratentorial white matter, brainstem, or spinal cord; and they are rarely simultaneously positive for anti-NMO antibodies. ${ }^{4,8-10}$ To avoid overdiagnosis, an international panel published a consensus guideline for testing and diagnosis, suggesting that criteria for anti-MOG encephalomyelitis include (1) monophasic or recurrent optic neuritis, myelitis, encephalitis, or a combination thereof; (2) radiographic or electrophysiologic evidence of demyelination; and (3) MOG IgG seropositivity via a cell-based assay that uses full-length human MOG antigen. ${ }^{11}$

Nevertheless, uncommon, heterogeneous features of anti-MOGassociated disease have been described, including seizures ${ }^{4,9-12}$ or cortical or leptomeningeal findings on imaging, ${ }^{4,10,12}$ suggestive of a novel anti-MOG-associated syndrome. First described in adults by Ogawa et al., ${ }^{13}$ this syndrome has been named FLAMES. ${ }^{4}$ Patients with FLAMES often present with focal or generalized seizures as an early symptom. ${ }^{4,13}$ In a case review of 20 patients with FLAMES, $85 \%$ had seizures, 70\% had headache, $65 \%$ had fevers, and $55 \%$ had a focal deficit that corresponded to the unilateral area of cortex involved on imaging. ${ }^{4}$ The presence of fever is noteworthy, as this can make it harder to rule out infectious causes and delay immunosuppression. Typical features of autoimmune demyelinating diseases, such as optic neuritis or myelitis, can precede, co-occur with, or succeed the FLAMES symptoms, ${ }^{4,13}$ and thus patients may meet diagnostic criteria only over an extended time. ${ }^{11}$

On imaging, patients with FLAMES characteristically present with unilateral cortical T2 hyperintensity, ${ }^{4,13}$ and may not initially meet the second diagnostic criterion requiring radiologic evidence of demyelination. ${ }^{11}$ Subcortical involvement, sometimes with enhancement, can evolve later, as seen in our patient. ${ }^{4,13}$ Findings can be bihemispheric, but are commonly unilateral. ${ }^{4,13}$ Six out of 20 patients described in Budhram et al. ${ }^{4}$ also demonstrated leptomeningeal enhancement.

Our patient responded to high-dose steroids, which was successful in all 24 previously reported FLAMES cases, ${ }^{4,13}$ and is a mainstay of acute therapy for anti-MOG-associated disease. ${ }^{5}$ Although there is no standard approach to maintenance therapy for MOG-associated illness, the prominent suspected role of antibody production in the pathophysiology of this disorder makes rituximab, which depletes B-cell precursors, a common choice. ${ }^{5}$ Though minimal specific data exist on the risk of relapse in FLAMES, a study of MOGantibody-positive children suggests that relapse occurs in roughly one-third of patients, and that older school-aged children (median age of 10 years) with higher initial antibody titers $(>1: 1,280)$ are most at risk by 24 months. ${ }^{14}$

The exact pathogenic mechanism of anti-MOG antibodies in human disease is unclear. ${ }^{8}$ Our patient had no CSF oligoclonal bands, which has been observed in FLAMES and other MOGassociated disorders, suggesting that anti-MOG disease may have a different neuroinflammatory mechanism than other demyelinating disorders. ${ }^{4}, 15$ Anti-MOG antibodies may bind to myelin, activate complement, and directly precipitate oligodendrocyte death. ${ }^{8}$ Alternatively, they may act more indirectly via antigen-presenting cell uptake leading to T-cell activation and cerebral inflammation. ${ }^{8}$ A third possibility is that anti-MOG antibodies are an epiphenomenon of a parallel neuroinflammatory process and are merely a convenient biomarker. ${ }^{4,8}$ Human pathology specimens from anti-MOG-positive patients demonstrate antibody and complement deposition, demyelination, and loss of MOG expression by oligodendrocytes, ${ }^{8,15}$ supporting at least some directly pathogenic role in anti-MOG-associated disease.

Questions about FLAMES include why gray matter rather than white matter is initially involved and why neuroimaging findings are unilaterally restricted. As FLAMES becomes more widely recognized, our understanding of the unique risk factors, clinical trajectory, radiographic profile, pathophysiology, and therapeutic options for this unusual condition will be clarified. 


\section{Acknowledgment}

The authors thank Kendall Nash, MD; Sharon Wietstock, MD; Carla Francisco, MD; William Soulsby, MD; Susan Kim, $\mathrm{MD}$, MMSc; Greta Peng, MD; and Manjiree Vikas Karandikar, MD, for their assistance with clinical management of this patient; and thank Daniel Lachance from the Mayo Clinic for providing information on the anti-MOG antibody assay.

\section{Study funding}

No targeted funding reported.

\section{Disclosure}

J. Russ is a member of the Neurology ${ }^{\circledR}$ Resident \& Fellow Section editorial team. C. Timbie, Y. Li, and E. GonzalezGiraldo report no disclosures relevant to the manuscript. Go to Neurology.org/ $\mathrm{N}$ for full disclosures.

\section{Appendix Authors}

\begin{tabular}{|c|c|c|}
\hline Name & Location & Contribution \\
\hline $\begin{array}{l}\text { Jeffrey B. } \\
\text { Russ, MD, } \\
\text { PhD }\end{array}$ & $\begin{array}{l}\text { University of } \\
\text { California San } \\
\text { Francisco }\end{array}$ & $\begin{array}{l}\text { Designed and conceptualized } \\
\text { study, participated in patient care, } \\
\text { analyzed data, drafted and } \\
\text { revised the } \\
\text { manuscript }\end{array}$ \\
\hline $\begin{array}{l}\text { Clare M. } \\
\text { Timbie, MD, } \\
\text { PhD }\end{array}$ & $\begin{array}{l}\text { University of } \\
\text { California San } \\
\text { Francisco }\end{array}$ & $\begin{array}{l}\text { Designed and conceptualized } \\
\text { study, participated in patient care, } \\
\text { analyzed data, drafted and } \\
\text { revised the } \\
\text { manuscript }\end{array}$ \\
\hline Yi Li, MD & $\begin{array}{l}\text { University of } \\
\text { California San } \\
\text { Francisco }\end{array}$ & $\begin{array}{l}\text { Designed and conceptualized } \\
\text { study, participated in patient care, } \\
\text { analyzed data, compiled imaging, } \\
\text { drafted and revised the } \\
\text { manuscript }\end{array}$ \\
\hline
\end{tabular}

Appendix (continued)

\begin{tabular}{|c|c|c|}
\hline Name & Location & Contribution \\
\hline $\begin{array}{l}\text { Ernesto } \\
\text { Gonzalez- } \\
\text { Giraldo, MD }\end{array}$ & $\begin{array}{l}\text { University of } \\
\text { California San } \\
\text { Francisco, CA }\end{array}$ & $\begin{array}{l}\text { Designed and conceptualized } \\
\text { study, participated in patient care, } \\
\text { analyzed data, compiled EEG } \\
\text { results, drafted and revised the } \\
\text { manuscript }\end{array}$ \\
\hline
\end{tabular}

\section{References}

1. Tufenkjian K, Lüders HO. Seizure semiology: its value and limitations in localizing the epileptogenic zone. J Clin Neurol 2012;8:243-250.

2. Uccelli A, Gattorno M. Neurological manifestations in autoinflammatory diseases. Clin Exp Rheumatol 2018;36(suppl 110):61-67.

3. Waters PJ, Komorowski L, Woodhall M, et al. A multicenter comparison of MOG-IgG cell-based assays. Neurology 2019;92:e1250-1255.

4. Budhram A, Mirian A, Le C, Hosseini-Moghaddam SM, Sharma M, Nicolle MW. Unilateral cortical FLAIR-hyperintense lesions in anti-MOG-associated encephalitis with seizures (FLAMES): characterization of a distinct clinico-radiographic syndrome. J Neurol 2019;266:2481-2487.

5. Hacohen Y, Banwell B. Treatment approaches for MOG-Ab-associated demyelination in children. Curr Treat Options Neurol 2019;21:2.

6. O'Connor KC, McLaughlin KA, De Jager PL, et al. Self-antigen tetramers discriminate between myelin autoantibodies to native or denatured protein. Nat Med 2007;13:211-217.

7. Armangue T, Olivé-Cirera G, Martínez-Hernandez E, et al. Associations of paediatric demyelinating and encephalitic syndromes with myelin oligodendrocyte glycoprotein antibodies: a multicenter observational study. Lancet Neurol 2020;19:234-246.

8. Reindl M, Waters P. Myelin oligodendrocyte glycoprotein antibodies in neurological disease. Nat Rev Neurol 2019;15:89-102.

9. Cobo-Calvo A, Ruiz A, D'Indy H, et al. MOG antibody-related disorders: common features and uncommon presentations. J Neurol 2017;264:1945-1955.

10. Cobo-Calvo A, Ruiz A, Maillart E, et al. Clinical spectrum and prognostic value of CNS MOG autoimmunity in adults: the MOGADOR study. Neurology 2018;90:e1858-e1869.

11. Jarius S, Paul F, Aktas O, et al . MOG encephalomyelitis: international recommendations on diagnosis and antibody testing. J Neuroinflammation 2018;15:134.

12. Hamid SHM, Whittam D, Saviour M, et al . Seizures and encephalitis in myelin oligodendrocyte glycoprotein IgG disease vs aquaporin 4 IgG disease. JAMA Neurol 2018;75:65-71.

13. Ogawa R, Nakashima I, Takahashi T, et al . MOG antibody-positive, benign, unilateral, cerebral cortical encephalitis with epilepsy. Neurol Neuroimmunol Neuroinflamm 2017;4:e322.

14. Hennes EM, Baumann M, Schanda K, et al. Prognostic relevance of MOG antibodies in children with an acquired demyelinating syndrome. Neurology 2017;89:900-908.

15. Höftberger R, Guo Y, Flanagan EP, et al. The pathology of central nervous system inflammatory demyelinating disease accompanying myelin oligodendrocyte glycoprotein autoantibody. Acta Neuropathol 2020;139:875-892. 


\section{Neurology}

\section{Clinical Reasoning: An 11-year-old girl with focal seizures, fevers, and unilateral, enhancing cortical lesions \\ Jeffrey B. Russ, Clare M. Timbie, Yi Li, et al.}

Neurology 2020;95;e3153-e3159 Published Online before print August 14, 2020

DOI 10.1212/WNL.0000000000010655

This information is current as of August 14, 2020

\section{Updated Information \&} Services

References

Permissions \& Licensing

Reprints including high resolution figures, can be found at: http://n.neurology.org/content/95/23/e3153.full

This article cites 15 articles, 4 of which you can access for free at: http://n.neurology.org/content/95/23/e3153.full\#ref-list-1

Information about reproducing this article in parts (figures,tables) or in its entirety can be found online at:

http://www.neurology.org/about/about_the_journal\#permissions

Information about ordering reprints can be found online: http://n.neurology.org/subscribers/advertise

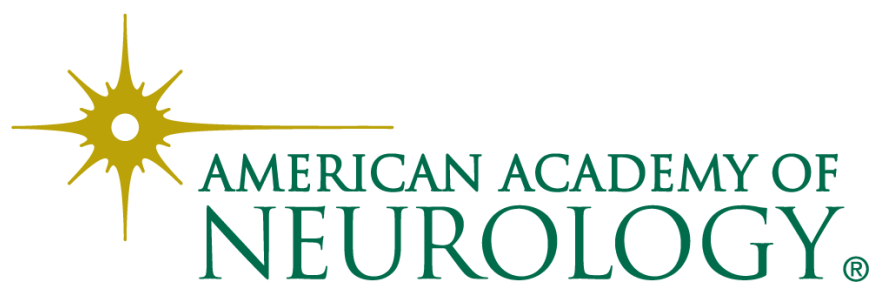

